\title{
HR practices, knowledge sharing and protection activities, and performance - A moderation model
}

Jorge F.S. Gomes ${ }^{1}$

ISEG - Lisbon School of Economics and Management, ULisboa, Portugal. E-mail: jorgegomes@iseg.ulisboa.pt

\section{Pia Hurmelinna*}

University of Oulu, P.O. Box 4600, 90014 University of Oulu, Finland. E-mail: pia.hurmelinna@oulu.fi

* corresponding author

\section{Heidi Olander}

School of Business and Management, Lappeenranta University of Technology, Finland. E-mail: heidi.olander@lut.fi

\begin{abstract}
Innovation and HRM practices are connected, but the nature of these linkages may not be completely understood. Practical examples where knowledge securing practices limit efficiency of creative work, and where rewarding established ways of work prevent new approaches from being tried, suggest that there are challenges. In this study, we examine the relationships between different forms of HRM practices, knowledge sharing and protection (i.e., knowledge activities), and performance outcomes. Our findings from empirical analysis among 150 firms suggest that HRM practices are positively related to subjective overall performance and innovation performance, and that knowledge sharing likewise has such a relationship with performance outcomes. Furthermore, when knowledge sharing is accompanied with HR practices targeted to securing knowledge, innovation performance can be improved. Knowledge securing also comes in play when it is combined with HR practices of personnel compensation and appraisal; in this case subjective performance is diminished. This leads us to suggest that companies might benefit from smart HRM systems.
\end{abstract}

Keywords: Human resource management, performance, innovation, knowledge sharing, knowledge protection

\section{Introduction}

In relation to innovation, human resource management (HRM) practices can be argued to function directly, through e.g. influencing creativity (Sanders et al., 2014), or indirectly,

\footnotetext{
${ }^{1}$ Authors listed in alphabetical order, equal contribution acknowledged.
} 
e.g. through shaping an innovative climate (Pereira \& Gomes, 2012); HRM practices seek such aims by securing the availability and presence of employees with innovative capabilities, promoting knowledge exchange, facilitating motivation, and fostering innovative climate (Sanders et al., 2014). On top of these goals, HR practices can be utilized to secure the uniqueness of knowledge assets and innovative knowledge that form the basis for capturing value and gaining adequate return from the investments put in innovative activities. How willing and able employees are to take care of confidential knowledge, and to look after the interests of their organization, are important issues both in terms of theory and practice (Porter Liebeskind, 1997; Hurmelinna-Laukkanen \& Puumalainen, 2007).

The challenge is that distinct HRM practices may encourage conflicting aims, or that they tend to promote one issue at a time - that is, they stimulate those features that they focus on - thus failing/forgetting the need to serve multiple, and not always consistent, organizational goals. For example, on one hand personnel compensation and appraisal are likely to facilitate productivity in the focus areas (that is, employees' search for rewards and recognition makes them act in a manner that fits the existing [production] systems), but one the other hand it cannot be taken for granted that they would ensure knowledge exchange or trial and error type of activities. Also, it has sometimes been questioned if such HR practices help employees to protect knowledge assets (Bulgurcu et al., 2010). In the same vein, knowledge sharing may become limited: it may be that rivalry over appreciation and compensation makes individuals guard their knowledge. Similarly, training personnel on knowledge protection and introducing information security policies, is likely to promote protection-related aspects, but such practices may not be helpful in terms of promoting knowledge sharing that would facilitate creative behaviour and innovative climate. In fact, those practices that support knowledge protection may even collide with practices supporting knowledge sharing (see Hannah \& Robertson, 2016, on challenges faced by employees with regard to following the rules set on handling confidential knowledge). Dealing with these aspects is therefore a multidimensional and a highly relevant managerial issue; managing HRM for innovation and efficiency is managing complex paradoxes and calls for balancing both at individual and organizational levels.

These aspects seem to go quite unnoticed in existing literature. Although leadership, management, and HR issues are frequently connected to innovativeness and innovation activities, often the focus is on creativity, both in terms of finding the ways to enhance it, and in terms of removing obstacles to creativity and innovation (Ribeiro et al., 2012). The paradoxical nature of HRM practices, where stability and change, and sharing and protection of knowledge may collide, is a research area that calls for further examination (Hannah \& Robertson, 2016).

This study addresses the questions of how different forms of HRM practices, and knowledge sharing and protection activities relate to different performance types, and how aligning HR-practices with knowledge sharing and protection activities is related to performance? In the following, we first discuss HRM systems and practices, and explicate how they have varying linkages to knowledge sharing and protection, and how these might then be related to performance outcomes - innovation and more comprehensive types. Empirical examination among 150 firms provides practical insight into these issues. Discussion on the findings and conclusions completes the paper. 


\section{HRM systems and practices supporting innovation}

The connection between HRM and innovation has attracted research since Miles and Snow (1978) first introduced their ideas about the connections between innovation strategies and the HRM function. In the following decades, advancements in the area were important, however, there is still much that has not been thoroughly studied or fully understood. The so called 'black box' of HRM research (Ferris et al., 1998; Gomes \& Sanders, 2012) indicates that the mechanisms to explaining influences of an organization's strategies on its performance through the HRM system, are still relatively undefined. In short, there are already a few studies that touch upon the issue of connecting HRM to innovation and other performance outputs (Guest, 2011), but research has yet to show a comprehensive and clear picture of such connections in modern organizations. These aspects would benefit from closer examination: which HR management practices are associated with various performance outcomes and how - e.g. in relation to which activities - are questions with high relevance.

\subsection{HRM practices - connection to knowledge protection and sharing}

Knowledge protection and sharing are activities where the opposing goals come visible and where HRM practices therefore become challenged. So far, these activities have been considered in a few instances with HR issues. Bulgurcu et al. (2010) and Hannah and Robertson (2016), for example, build their studies on the issues of confidentiality, and consider the reasons for employees not to follow the knowledge securing practices of a firm. In some cases, this failure to protect knowledge (i.e., emergence of unwanted leakages, is about unawareness, sometimes it is simple neglected, and in some cases the rules are deliberately bent or broken so as to allow efficient work (Bulgurcu et al., 2010). Rarely the question is about employees abusing the organization, even if such cases could be possible due to disappointment with the (former) employer (see Olander et al., 2016 for redundancy-related knowledge mobility), or knowingly neglecting confidentiality rules in order to benefit oneself (Husted et al., 2013). Most often mishaps in knowledge protection activity are about the inability to understand the damage that breaking knowledge protection rules causes (Husted and Michailova, 2010; Ritala et al., 2015). Managers can address these issues through continuous monitoring, and by evaluating, for example, the trustworthiness of employees already during the recruitment interviews (Olander and Hurmelinna-Laukkanen, 2015). In general, the HR practices that are targeted towards limiting unwanted knowledge flows, i.e., knowledge securing practices, can cover means such as non-disclosure agreements, confidentiality clauses, enforcing non-competition agreements (applicable only with certain employees), educating employees on confidentiality issues, motivational aspects for following information security rules, sanctions for breaking the rules, and controlling and restricting access, (Baughn et al., 1997; Bulgurcu et al., 2010; Hannah, 2005; Hannah and Robertson, 2016; Olander et al., 2015; O’Neill and Adya, 2007; Porter Liebeskind, 1996;1997).

Promotion of knowledge sharing has likewise been discussed in earlier studies (e.g., Cabrera and Cabrera, 2005; Donate and Guadamillas, 2015). It is frequently noted that employees are highly important for an organization as they possess information and knowledge that is needed and valuable in process improvement and innovation creation (e.g., Alegre et al., 2013; Camelo-Ordaz et al., 2011). Knowledge sharing activity allows spread of the knowledge through various channels. In this sense, HRM can support - even 
ensure - knowledge sharing activity. HRM can facilitate presence of knowledgeable employees that have enough common ground to efficiently share and utilize knowledge, and also generate new intellectual assets. In particular, recruitment and dismissal practices are of importance in this regard (see, e.g., Bae and Lawler, 2000). At the same time, increasing security about the job, ensuring person-job and person-organization fit (see, e.g., Boon et al., 2011), and promoting commitment and involvement may boost the levels of knowledge sharing among the established personnel (Camelo-Ordaz et al., 2011). Compensation and appraisal practices may, likewise, play a central role in this kind of activity (Delery and Doty, 1996; Sanders et al., 2014). Surely, there is a risk of internal competition becoming so fierce that individual employees start to guard their knowledge, or a possibility of suboptimal alignment of incentive systems, but in general, these practices could be considered to be relevant for knowledge sharing.

A more notable challenge is, as suggested above, that knowledge protection and sharing are by default at least partly opposing; knowledge that is heavily protected from being transferred is not likely shared efficiently, and knowledge that is disseminated openly and extensively cannot really be kept within a specific sphere for exclusive utilization (see, e.g., Hannah and Robertson, 2016). This also has implications in the area of HRM. As Hurmelinna-Laukkanen et al. $(2016,166)$ note, even if the need for both knowledge sharing and protection has been acknowledged, "how to achieve these seemingly contradicting goals is another issue, which is yet to be resolved (Kale et al. 2000; Yang et al. 2014)." If this can be accomplished, the performance of an organization may be positively affected. These issues are discussed in the following.

\subsection{Impact on performance and research goal}

Earlier studies have suggested that HRM systems are related to the financial and innovation performance of the firm (Boselie et al., 2005; Hurmelinna-Laukkanen and Gomes, 2012). This thought comes from the expectation that when employees know what is expected from them and are motivated to act according to the goals of their organizations, they will be engaged, motivated, and committed, and hence better results can be achieved. At the same time, the difficulties of connecting HRM directly to performance have been acknowledged, and therefore empirical studies have been exploring the role of various factors in the HRMperformance connection (see, e.g., Boselie et al., 2005; Guest, 1997; Wright and Gardner, 2003).

The current research follows this line of enquiry, by examining the relationships between HRM practices and performance, on one hand, and knowledge sharing and protection activities, on the other hand. The reasoning is that, in some industries more than in others, balancing knowledge sharing with knowledge protection is a critical capacity that companies need to develop, and HRM practices can play a pivotal role in such capacity building. In fact, following the above sections, industries which are heavily dependent on information and knowledge, need to have in place a set of HRM practices that are capable of stimulating employees' urge to share ideas, creativity, and knowledge, but also the wisdom to protect knowledge from leaving the organization. Whether or not this is achieved, is a matter of designing the right set of HRM practices and securing their positive impact on performance.

Given the relatively exploratory nature of this study, a set of hypotheses was put forward based on a research model in which performance depends, first, on HRM practices 
and, second, knowledge sharing and protection activities as antecedents. Moreover, these antecedents are considered to operate in interaction.

The first two hypotheses state a positive relationship between HRM practices and performance. Performance in the current research was measured in two ways: subjective (evaluation on the overall performance of the firm) and innovation performance (introduction of innovation in different areas):

H1: There is a positive relationship between the different HR practices and subjective performance;

$\mathrm{H} 2$ : There is a positive relationship between the different HR practices and innovation performance;

Furthermore, following from the above discussion, performance is also likely to be affected by specific knowledge related activities and management practices, such as sharing and protection of knowledge. This leads to formulating the following hypotheses:

H3a: There is a positive relationship between knowledge sharing activities and subjective performance;

$\mathrm{H} 3 \mathrm{~b}$ : There is a positive relationship between knowledge protection activities and subjective performance;

H4a: There is a positive relationship between knowledge sharing activities and innovation performance;

H4b: There is a positive relationship between knowledge protection activities and innovation performance

Finally, following especially from the above notion that HR practices likely yield best results when they are aligned with firm goals and activities, the interaction of HR practices and knowledge activities is taken under examination. HRM may influence the linkages between knowledge activities and performance, especially considering the match of HR practices to firm goals in this respect. Literature has established a clear influence of HRM on performance, but the linkages of knowledge protection and sharing activities with performance are more ambiguous, which increases the need to consider these issues. In sum, a moderator-type of research seemed to be appropriate to capture these complex relationships between the three subject matters. The following shows the rationale on a general level:

H5a: The different HRM practices moderate the relationship between knowledge sharing activities and subjective performance;

H5b: The different HRM practices moderate the relationship between knowledge protection and subjective performance;

H6a: The different HRM practices moderate the relationship between knowledge sharing and innovation performance;

H6b: The different HRM practices moderate the relationship between knowledge protection and innovation performance. 
Figure 1 below illustrates our hypotheses and how they shape relationships between the concepts under examination.

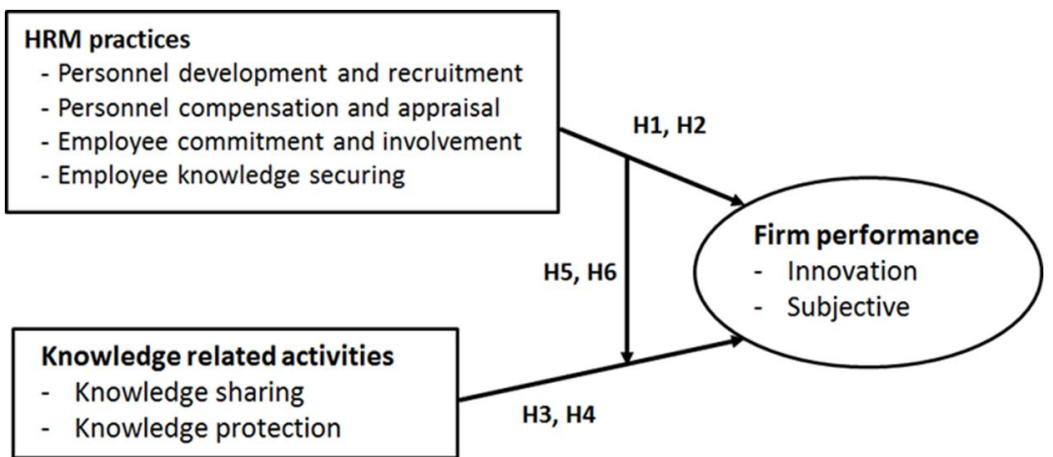

Figure 1. The conceptual model

\section{Methods}

\subsection{Procedure and participants}

The data were collected from 150 technology-oriented firms (a 12\% return rate) using a survey conducted in Finland during 2012. The initial sample included all members of the Federation of Finnish Technology Industries, a national industry association, which comprised 1,273 firms from machinery and metal, electronics, information technology, and planning and consulting industries. The sample selection had a threshold of at least 10 employees per firm. Following key informant logic (Kumar et al., 1993), the questionnaires were sent to professionals with a sufficient level of seniority to be able to respond to the questions, i.e., to the Chief Executive Officer of each firm.

\subsection{Measures}

The data were collected with the help of a structured questionnaire that consisted of scales from previous studies, and some original item sets. The scales used in this study were aimed to measure individual perceptions of HR practices, two performance dimensions, and knowledge protection and sharing activities. The following variables were captured in the questionnaire (appendix 1 shows all the items, as well as the scales and original sources):

A) HRM practices: literature discusses extensively what an HRM practice might be. Due to the limited consensus regarding what an HRM practice is, or what the most central HRM practices are, the current work followed several authors (see appendix 1), and comprised four HRM practices, of which the last one is expected to capture specific HR practices that target securing of knowledge:

i) Personnel Development and Recruitment: 15 items (Alpha=0,93)

ii) Personnel Compensation and Appraisal: 9 items (Alpha=0,82)

iii) Employee Commitment and Involvement: 12 items (Alpha=0,92)

iv) Employee Knowledge Securing practices: 5 items (Alpha=0,75) 
B) Efficiency of Knowledge-related activities: as exposed above, these were divided into sharing and protecting knowledge activities:

v) Knowledge Sharing activities: 6 items $($ Alpha=0,87)

vi) Knowledge Protection activities ${ }^{1}: 4$ items (Alpha=0,86)

C) Performance: two forms of performance were used:

vii) Subjective Performance: 13 items (Alpha $=0,82)$

viii) Innovative Performance: 4 items $($ Alpha $=0,74)$

\section{Analyses and findings}

Data analyses was carried out with correlation, regression, and hierarchical regression analyses. Following the example of earlier studies, four variables were utilized as controls: share of R\&D from turnover, size and age of the organization, and turnover. Due to the non-normality character of some of the control and independent variables, scales transformation was performed before the main analyses. Table 1 shows the descriptive statistics and the correlations between the main variables.

Table 1 Correlation matrix and descriptive statistics

\begin{tabular}{|c|c|c|c|c|c|c|c|c|}
\hline & $\begin{array}{l}\text { Mean } \\
(\mathrm{SD})\end{array}$ & 1. & 2. & 3. & 4. & 5. & 6. & 7. \\
\hline $\begin{array}{l}\text { Knowledge protection } \\
\text { activities }\end{array}$ & $\begin{array}{c}2.1 \\
(1.16) \\
\end{array}$ & -.144 & .026 & .039 & .019 & $-.202^{*}$ & -.109 & -.020 \\
\hline $\begin{array}{l}\text { 1. Knowledge sharing } \\
\text { activities }\end{array}$ & $\begin{array}{c}4.1 \\
(1.39)\end{array}$ & & $.511^{* *}$ & $.359^{* *}$ & $.492^{* *}$ & .160 & $.257^{* *}$ & $.343^{* *}$ \\
\hline $\begin{array}{l}\text { 2. Per. development } \\
\& \text { recruitment }\end{array}$ & $\begin{array}{c}4.4 \\
(1.06)\end{array}$ & & & $.633^{* *}$ & $.713^{* *}$ & .157 & $.437^{* * *}$ & $.569^{* *}$ \\
\hline $\begin{array}{l}\text { 3. Pers. compensation } \\
\& \text { appraisal }\end{array}$ & $\begin{array}{c}4.4 \\
(0.90) \\
\end{array}$ & & & & $.644^{* *}$ & .116 & $.302^{* *}$ & $.491^{* *}$ \\
\hline $\begin{array}{l}\text { 4. Commitment \& } \\
\text { involvement }\end{array}$ & $\begin{array}{c}5.3 \\
(1.02) \\
\end{array}$ & & & & & .101 & $.305^{* *}$ & $.529^{* *}$ \\
\hline $\begin{array}{l}\text { 5. Knowledge } \\
\text { securing practices }\end{array}$ & $\begin{array}{r}5.3 \\
(1.15) \\
\end{array}$ & & & & & & .089 & .010 \\
\hline $\begin{array}{l}\text { 6. Subjective } \\
\text { performance }\end{array}$ & $\begin{array}{c}4.2 \\
(0.82)\end{array}$ & & & & & & & $468^{* *}$ \\
\hline $\begin{array}{l}\text { 7. Innovative } \\
\text { performance }\end{array}$ & $\begin{array}{c}4.36 \\
(0.93)\end{array}$ & & & & & & & \\
\hline
\end{tabular}

\footnotetext{
${ }^{1}$ Small values indicate high efficiency in knowledge protection: any emerging negative relationship therefore suggest a positive relationship with the other variable.
} 
From the Table 1, one can observe an interesting pattern of correlations. Firstly, HRM practices seem to be statistically associated with both subjective and innovative performance measures, which sanction the value and effectiveness of HRM practices in the respondent companies.

Subsequent multiple regression analyses taking the four HR practices (development \& recruitment, compensation \& appraisal, commitment \& involvement, and knowledge securing) together show that the predictive value of practices is higher for innovative performance $\left(\mathrm{R}_{\mathrm{a}}{ }_{\mathrm{a}}=0,377\right)$, than for subjective performance $\left(\mathrm{R}_{\mathrm{a}}{ }_{\mathrm{a}}=0,267\right)$. Regressions also indicate that the variable development and recruitment practices is the most important predictor for innovation performance $(\mathrm{B}=0.312$, $\mathrm{t}$-value $=3.432, \mathrm{p}=0.001)$, followed by compensation and appraisal $(\mathrm{B}=260$, $\mathrm{t}$-value=2.561, $\mathrm{p}=0.012)$. Employee knowledge securing practices point toward a negative relationship, although only moderately significant one $(\mathrm{B}=-0.099, \mathrm{~T}$-value $=-1.636, \mathrm{p}=0.105)$. Personnel development and recruitment also is positively related to subjective performance $(B=0.352$, $t$-value $=3.684$, $\mathrm{p}=0.000)$. A small multicollinearity effect was detected between the first three practices. All in all, these results only partially support $\mathrm{H} 1$ and $\mathrm{H} 2$, but it still is likely that some HRM practices influence performance indicators.

Secondly, our data shows that knowledge protection activities are not correlated with any of HRM practices or any of the performance measures. Conversely, knowledge sharing activities are significantly correlated with all HRM practices except knowledge securing, and they are also associated with both subjective and innovative performance.

Multiple regression analysis with performance measures, taking knowledge sharing and protection activities together, confirmed the bigger weight of the former over the latter, hence confirming $\mathrm{H} 3 \mathrm{a}$ and $\mathrm{H} 4 \mathrm{a}$ (knowledge sharing activities and subjective performance $[\mathrm{B}=0.159, \mathrm{t}$-value $=2.620, \mathrm{p}=0.010]$, and innovation performance $[\mathrm{B}=0.177, \mathrm{t}=3.023$, $\mathrm{p}=.003]$ ), but not $\mathrm{H} 3 \mathrm{~b}$ and $\mathrm{H} 4 \mathrm{~b}$ (knowledge protection activities and performance).

These finding suggest that general HRM practices in the respondent organizations seem to be designed towards stimulating sharing of knowledge, rather than promoting its protection. The fact that there is no association between knowledge sharing activities and specific activities designed at managing individuals' knowledge securing suggests that HRM is still pretty much aiming at generic behaviours in the organization, and do not care for managing the balance between knowledge protection and knowledge sharing. It is like generic HRM practices are operating to send the message "share knowledge in this company...", but are not capable of transmitting its important complement: “...but do not share it with the outside world". In light of this, employees may get a sense that talking about critical knowledge inside or outside the company is not regulated. In sum, these findings indicate that the respondent companies value and respect knowledge sharing practices, and see their contribution to performance in the organization; however, they do not have a well-developed policy regarding protecting sensitive knowledge from leaving or leaking to the outside.

The last hypotheses were investigated with hierarchical regression analyses. Control variables were entered first, then independent variables, and finally the moderator effects were examined. Both control and independent variables were mean-centred before running the regressions. Some outliers were identified and removed from all regressions. In total, eight regressions were performed for each dependent variable, 16 in total.

Contrary to expected, only two of these 16 regressions showed significant effects, lending some support to H5b (The different HRM practices moderate the relationship between knowledge protection activities and subjective performance) and H6a: (The 
different HRM practices moderate the relationship between knowledge sharing activities and innovation performance) - no support was found for H5a or H6b. Due to the considerable amount of information, only these two cases are shown in tables 2 and 3 below.

Table 2 Hierarchical regression analysis for variables predicting subjective performance

\begin{tabular}{|c|c|c|c|c|c|c|c|c|c|c|}
\hline \multicolumn{2}{|c|}{ Variables } & \multicolumn{3}{|c|}{ Model 1} & \multicolumn{3}{|c|}{ Model 2} & \multicolumn{3}{|c|}{ Model 3} \\
\hline & & $B$ & $S E B$ & $\beta$ & $B$ & $S E B$ & $\beta$ & $B$ & $S E B$ & $\beta$ \\
\hline \multirow{4}{*}{ 㭶 } & Share R\&D & 0.43 & 0.18 & $0.23 *$ & 0.35 & 0.19 & 0.19 & 0.28 & 0.19 & 0.15 \\
\hline & Size & 0.52 & 0.34 & 0.32 & 0.41 & 0.35 & 0.25 & 0.47 & 0.34 & 0.28 \\
\hline & Age & -0.16 & 0.22 & -0.07 & -0.20 & 0.22 & -0.09 & -0.23 & 0.22 & -0.10 \\
\hline & Turnover & -0.01 & 0.28 & -0.01 & 0.03 & 0.28 & 0.02 & 0.02 & 0.27 & 0.01 \\
\hline \multirow{2}{*}{$\begin{array}{l}\overrightarrow{0} \\
\frac{0}{0} \\
\frac{0}{0} \\
\frac{0}{0}\end{array}$} & K-protection & & & & -0.04 & 0.08 & -0.05 & 0.03 & 0.08 & 0.04 \\
\hline & $\begin{array}{l}\text { Pers. compensation \& } \\
\text { appraisal }\end{array}$ & & & & 0.12 & 0.08 & 0.16 & 0.13 & 0.08 & 0.17 \\
\hline $\begin{array}{l}\frac{\overline{0}}{\pi} \\
\frac{\pi}{0} \\
\frac{0}{0} \\
\Sigma\end{array}$ & $\begin{array}{l}\text { K-protection X Pers. } \\
\text { compensation \& } \\
\text { appraisal }\end{array}$ & & & & & & & -0.15 & 0.06 & $-0.25 *$ \\
\hline \multicolumn{2}{|l|}{$\mathrm{R}^{2}$} & \multicolumn{3}{|c|}{$.375^{*}$} & \multicolumn{3}{|c|}{.405} & \multicolumn{3}{|c|}{$.460 *$} \\
\hline \multicolumn{2}{|c|}{$\mathrm{F}$ for change in $\mathrm{R}^{2}$} & \multicolumn{3}{|c|}{$3.804 *$} & \multicolumn{3}{|c|}{$2.984 *$} & \multicolumn{3}{|c|}{$3.451^{*}$} \\
\hline
\end{tabular}

Table 3 Hierarchical regression analysis for variables predicting innovation performance

\begin{tabular}{|c|c|c|c|c|c|c|c|c|c|c|}
\hline \multicolumn{2}{|c|}{ Variables } & \multicolumn{3}{|c|}{ Model 1} & \multicolumn{3}{|c|}{ Model 2} & \multicolumn{3}{|c|}{ Model 3} \\
\hline & & $B$ & $S E B$ & $\beta$ & $B$ & $S E B$ & $\beta$ & $B$ & $S E B$ & $\beta$ \\
\hline \multirow{4}{*}{$\begin{array}{l}\overline{0} \\
\stackrel{0}{0} \\
0\end{array}$} & Share R\&D & 0.53 & 0.22 & $0.24 *$ & 0.48 & 0.23 & 0.21 & 0.51 & 0.22 & $0.23 *$ \\
\hline & Size & 0.87 & 0.40 & $0.48 *$ & 0.87 & 0.40 & $0.48 *$ & 0.79 & 0.38 & 0.44 \\
\hline & Age & 0.07 & 0.28 & 0.02 & 0.10 & 0.29 & 0.03 & -0.01 & 0.28 & -0.00 \\
\hline & Turnover & -0.30 & 0.32 & -0.20 & -0.34 & 0.33 & -0.23 & -0.32 & 0.31 & -0.21 \\
\hline \multirow{2}{*}{ 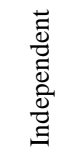 } & K-sharing & & & & 0.14 & 0.10 & 0.14 & 0.18 & 0.10 & 0.18 \\
\hline & $\begin{array}{l}\text { Knowledge securing } \\
\text { practices }\end{array}$ & & & & -0.01 & 0.10 & -0.01 & 0.05 & 0.10 & 0.05 \\
\hline \multirow{2}{*}{$\begin{array}{l}\overline{0} \\
\frac{\pi}{0} \\
\frac{0}{0} \\
0 \\
\Sigma\end{array}$} & K-sharing X & & & & & & & & & \\
\hline & $\begin{array}{l}\text { Knowledge securing } \\
\text { practices }\end{array}$ & & & & & & & 0.30 & 0.10 & $0.30 *$ \\
\hline \multicolumn{2}{|l|}{$\mathrm{R}^{2}$} & \multicolumn{3}{|c|}{$.364 *$} & \multicolumn{3}{|c|}{.386} & \multicolumn{3}{|c|}{$.481 *$} \\
\hline \multicolumn{2}{|c|}{$\mathrm{F}$ for change in $\mathrm{R}^{2}$} & \multicolumn{3}{|c|}{$3.511 *$} & \multicolumn{3}{|c|}{2.634} & \multicolumn{3}{|c|}{$3.837 *$} \\
\hline
\end{tabular}


From these two tables, a few points are worth mentioning. Firstly, combining knowledge sharing activity with knowledge securing practices seems to generate positive change in terms of innovation performance. Awareness of the need to secure knowledge assets, and developing the skills to do so limit excessive knowledge transfer. Innovation performance is subsequently affected, as there is more incentive to produce new innovation: others cannot capture the generated outputs as easily.

Secondly, the interaction of knowledge protection activity and the HR practices of personnel compensation and appraisal generates negative outcomes with regard to subjective performance. This finding can be connected to the notions of Bulgurcu et al. (2010) on the limited power of rewards used in connection to knowledge protection. Our findings could be interpreted so that personnel compensation and appraisal can yield adverse effects if it strengthens protective approach too much. While hypotheses 5 and 6 do not receive much support, the data suggests that there might be aspects on the alignment to be revealed.

\section{Conclusions}

As a conclusion, we can note that there are HRM practices (development \& recruitment, compensation \& appraisal, in particular) that relate positively to subjective and innovation performance, and that of these performance indicators, especially innovation performance can be affected. Of knowledge-related activities, knowledge sharing relates positively to both performance types. On the other hand, safeguarding knowledge only emerges as relevant when it is combined with other factors: it seems that knowledge protection as an activity, and knowledge securing as a HR practice work towards better performance when they are contained to a suitable level: over-emphasis is harmful, but some practices are inevitably needed However, more research is needed to confirm these ideas.

By bringing forward these findings, our study contributes to the existing knowledge by bridging two research streams: HRM and innovation. We provide evidence on the nuances regarding the relationships between $\mathrm{HRM}$ and performance outcomes, and involve organization's activities into the discussion. This allows tapping into the 'black box', i.e., in explaining the impact of HRM systems on organizational-level variables such as performance (see Gomes \& Sanders, 2012; Boselie et al., 2005). Understanding the limits and 'best uses' of individual HRM practices increases comprehension of when and for which purposes varying HRM mechanisms suit best. Also, this enables evaluation of their interactions in a novel way, and this triggers practical and managerial contributions. It may be, for example, that a specific HR practice is valuable - even necessary - to a certain point, but after that it needs to be replaced with other activities and practices in order to produce the final performance outputs. The earlier findings of Clark and Colling (2005) and Popaitoon and Siengthai (2014) in the context of project management point towards this direction.

Communicating the change in emphases to employees is, of course, a central task of management. In fact, an important managerial implication is that rather than developing more or better HR practices, we argue that managers working especially in companies operating in highly creative and innovative sectors should be focused on developing smarter HR systems that reflect the complex interplay between securing sensitive knowledge, on one hand, and spreading useful knowledge to generate more value, on the 
other hand. This logic should also be extendable to securing productivity (exploitation and utilization of existing resources and competitive advantages), and supporting renewal and change (exploration of new opportunities), that is, to balancing and changing between differing goals. Placing managerial attention to the alignment of the activities and goals of the organization and its HRM practices is highly relevant, and dynamism may be needed so as to ensure that different opportunities and threats can be handled efficiently. Different means indeed lead to different ends. This means that when the emphases placed on specific activities change, HRM has to be responsive and the practices that are employed need to be adapted accordingly. Understanding the applicability of HR practices for different purposes allows firms to build such smart HRM systems that they need in the continuously changing business environments.

This study has several limitations. First of all, the data were collected in one specific geographical area, Finland. The country is known for its viable legal system and high trust business relationships inherent in the relatively small market area. Both of these issues could affect the results: trust in others can make knowledge sharing easier, and strong and efficient legal system enhances the power of legal knowledge protection mechanisms, and therefore makes relationships and behaviour more predictable. The co-existence of trust and small market can actually also lessen the need for formal protection in the first place, which may explain the limited attention paid to knowledge protection. Second, the sample size, while rather sufficient for the analyses in question, could be larger: Bigger datasets could potentially expose some more underlying relationships. Moreover, testing for mediating effects might also reveal important aspects on the alignment of the different factors. One limitation is that the sample concerns companies in technology industries. Technology-intensive companies may face different kinds of challenges from those of other companies. However, the technology-intensiveness makes a fruitful context for examination of developed HRM practices and knowledge sharing and protection activities, as the firms included in the sample are likely paying attention to these issues as the human resources and action of the employees in terms of knowledge sharing are vital part of their innovativeness.

The results and limitations suggest paths for further studies. Firstly, as the data is collected in a single-country setting, we encourage further surveys to be conducted in different countries with different cultures. Surveys conducted in less technology-oriented industries could also be beneficial to explore the differences in knowledge sharing and protection actions of employees from one industry to another. More complicated models are likely needed as well, and for this, some measures may need to be modified. Nevertheless, we hope that the findings of this study can provide ground for such works.

\section{References}

Alegre J, Sengupta K \& Lapiedra R. (2013). Knowledge management and innovation performance in a high-tech SMEs industry. International Small Business Journal, 31, 454-470.

Bae, J., \& Lawler, J. J. (2000). Organizational and HRM strategies in Korea: Impact on firm performance in an emerging economy. Academy of Management Journal, 43(3), 502-517. 
Baughn, C.C, Stevens, J.H., Denekamp, J.G., \& Osborn, R.N. (1997). Protecting intellectual capital in international alliances. Journal of World Business 32(2), 103117.

Boon, C., Den Hartog, D.N., Boselie, P. \& Paauwe, J. (2011). The relationship between perceptions of HR practices and employee outcomes: Examining the role of personorganisation and person-job fit, The International Journal of Human Resource Management, 22(1), 138-162.

Bulgurcu, B., Cavusoglu, H. \& Benbasat, I. (2010). Information security policy compliance: An empirical study of rationality-based beliefs and information security awareness. MIS Quarterly, 34(3), 523-548.

Cabrera, E. F., \& Cabrera, A. (2005). Fostering knowledge sharing through people management practices. The International Journal of Human Resource Management, 16(5), 720-735.

Camelo-Ordaz C, Garcia-Cruz J, Sousa-Ginel E \& Valle-Cabrera R. (2011). The influence of human resource management on knowledge sharing and innovation in Spain: the mediating role of affective commitment. The International Journal of Human Resource Management, 22, 1442-1463.

Clark, I. \& Colling, T. (2005). The management of human resources in project management-led organizations. Personnel Review, 34, 178-191.

Delery, J.E. \& Doty, D.H. (1996). Modes of theorizing in strategic human resource management: Tests of universalistic, contingency, and configurational performance predictions, Academy of management Journal, 39(4), 802-835.

Donate, M. J., \& Guadamillas, F. (2015). An empirical study on the relationships between knowledge management, knowledge-oriented human resource practices and innovation. Knowledge Management Research \& Practice, 13(2), 134-148.

Ferris, G.R., Arthur, M.M., Berkson, H.M., Kaplan, D.M., Harrell-Cook, G. \& Frink, D.D. (1998). Toward a social context theory of the human resource managementorganization effectiveness relationship. Human Resource Management Review, 8(3), 235-264.

Gomes, J.F.S. \& Sanders, K. (2012). Formal and informal HRM: Implications for the HRM process perspective. Caucus at the Academy of Management, Annual Meeting, August 3-7, Boston, MA.

Guest, D. (1997). Human resource management and performance: a review and research agenda. International Journal of Human Resource Management, 8(3), 263-276.

Guest, D. (2011). Human resource management and performance: Still searching for some answers. Human Resource Management Journal, 21, 3-13.

Hannah, D.R. (2005). Should I keep a secret? The effects of trade secret protection procedures on employees' obligations to protect trade secrets. Organisation Science 16(1), 71-84

Hurmelinna-Laukkanen, P., Gomes, J.F.S. \& Olander, H. (2016). What Did You Expect to Happen? Aligning HR Practices with Knowledge Management Outcomes. In: Entrepreneurship, Business and Economics - Vol. 1, Eurasian Studies on Business and Economics 3/1. Bilgin, Mehmet Huseyin \& Danis, Hakan (Eds.), Springer International Publishing, Switzerland, 165-182.

Husted, K. \& Michailova, S. (2010).Dual allegiance and knowledge sharing in inter-firm R\&D collaborations. Organization Dynamics, 39(1), 37-47.

Husted, K., Michailova, S. \& Olander, H. (2013).Dual allegiance, knowledge sharing, and knowledge protection: an empirical examination. International Journal of Innovation Management, 17 (6), 1340022-1-1340022-33. 
Kale, P., Singh, H. \& Perlmutter, H. (2000). Learning and protection of proprietary assets in strategic alliances: Building relational capital, Strategic Management Journal, 21(3), 217-237.

Kumar, N., Stern, L. \& Anderson, J. (1993). Conducting interorganizational research using key informants. Academy of Management Journal, 36, 1633-1651.

Miles, R.E. \& Snow, C.C. (1978). Organizational strategy, structure, and process. New York: McGraw-Hill Book Co.

Olander, H. \& Hurmelinna-Laukkanen, P. (2015). Proactive HRM for reducing knowledge risks - evaluating commitment and trustworthiness, International Journal of Innovation Management, 19 (6), 1540011

Olander, H., Hurmelinna-Laukkanen, P. \& von Zedtwitz, M. (2016) Intentional or not The nature and dimensions of knowledge mobility, ISPIM Conference, 19-22 June 2016, Porto Portugal.

O'Neill, B.S. \& Adya, M. (2007). Knowledge sharing and the psychological contract. Journal of Managerial Psychology, 22(4): 411-436.

Pereira, C.M.M. \& Gomes, J.S.F. (2012). The strength of human resource practices and transformational leadership: Impact on organisational performance. The International Journal of HRM. 23(20), 4301-4318.

Popaitoon, S., \& Siengthai, S. (2014). The moderating effect of human resource management practices on the relationship between knowledge absorptive capacity and project performance in project-oriented companies. International Journal of Project Management, 32, 6, 908-920.

Porter Liebeskind, J. (1997). Keeping organizational secrets: Protective institutional mechanisms and their costs. Industrial and Corporate Change, 6, 623-663.

Ribeiro, T., Coelho, J.P. \& Gomes, J.F.S. (2011). HR Strength, situation strength and improvisation behavior. Management Research, 9(2), 118-136.

Ritala, P., Olander, H., Michailova, S. \& Husted, K. (2015). Knowledge sharing, knowledge leaking and relative innovation performance: An empirical study, Technovation, 35, 22-31.

Sanders, K., Shipton, H. \& Gomes, J.F.S. (2014). Guest Editors' Introduction: Is the HRM Process important? Past, current, and future challenges. Human Resource Management, 53(4), 489-503.

Wright, P. M. \& Gardner, T. M. (2003). The human resource-firm performance relationship: methodological and theoretical challenges, in Holman, D., T.D. Wall, C. W. Clegg, P. Sparrow \& A. Howard (eds): The New Workplace: A Guide to the Human Impact of Modern Working Practices. London: John Wiley\&Sons.

Yang, S.M., Fang, S.C., Fang, S.R., \& Chou, C.H. (2014). Knowledge exchange and knowledge protection in interorganizational learning: The ambidexterity perspective. Industrial Marketing Management, 43(2), 346-358. 


\section{Appendix 1: Items and scales}

Personnel Development and Recruitment (Bae \& Lawler, 2000; Delery \& Doty, 1996)

We use a lot of money on the training and development of our personnel

We provide opportunities for the training and development of personnel

We make different kinds of training available

We utilize a systematically structured training process

We consider the training of our personnel a high priority

We provide extensive training for general skills

Our employees have very little future within this organization (reverse item) *

Our employees have clear career paths within the organization

Employees' career aspirations within the company are known by their supervisors

We provide opportunities for job rotation

We put a lot of effort into recruiting the right persons

We spend a lot of money to recruit the right persons

We hire people with general rather than specific skills

We place great importance on the staffing process

We focus on long-run employee potential when selecting staff

We have high/extensive selection criteria in our firm

* Item removed from final scale computation

Personnel Compensation and Appraisal (Wright et al., 1999; Bae \& Lawler, 2000; modified)

Our pay is tied to employees' individual performance

There are major differences in the pay of personnel in similar positions

Our employees are also compensated for with other means than money

Employees get feedback for a job well done

Employees are personally acknowledged from a job well done

A lot of effort is put to measuring employee performance

Raises, promotions, etc. are closely tied to performance appraisal

Individual performance is regularly discussed with employees

Many people provide their input to performance evaluation

Employee Commitment and Involvement (Guest, 2003; Ahmad \& Schroeder, 2003)

Employees are provided with information on business plans

Employees are provided with information on financial objectives

Employees are provided with information on the firm's performance

Employees are provided with information on important initiatives

Direct feedback from employees is collected regularly

We pursue to gather opinions from many employees through issues discussed in teams

Employee teams are encouraged to try and solve business-related problems

In the past 3 years, many problems have been solved in small groups

We try our best to keep the promises made to our employees

We conduct ourselves ethically towards our employees

We conduct ourselves rightfully towards our employees

We try our best to take the employees' benefit into account

Employee Knowledge Securing Practices (Hurmelinna-Laukkanen, 2012)

Educating personnel on IPR issues 
Educating personnel on secrecy with regard to business critical knowledge

Making personnel committed to the firm

Small personnel turnover/minimizing it

Increasing the personnel's loyalty to the firm

Efficiency of Knowledge Protection Activities (new measure adapted and extended from Ritala et al., 2015 - small values indicate that protection has been successful)

Our employees accidentally leak business critical knowledge to our partners

Our employees accidentally leak business critical knowledge in other situations

Our employees leak business critical knowledge on purpose to our partners

Our employees leak business critical knowledge on purpose in other situations

Efficiency of Knowledge Sharing Activities (new measure adapted and extended from Ritala et al., 2015)

Our employees share their work reports and official documents with co-workers within the same firm

Our employees share their work reports and official documents with people employed by the firm's partners

Our employees share their manuals and methodologies with co-workers within the same firm Our employees share their manuals and methodologies with people employed by the firm's partners

Our employees share their experience or know-how with co-workers within the same firm

Our employees share their experience or know-how with people employed by the firm's partners

Subjective Performance (Delaney \& Huselid, 1996; Pertusa-Ortega et al., 2009; Alegre \& Chiva, 2008)

Growth in sales

Profitability

Market share

Market growth

Employment growth

Cash flow

Returns of investment

Replacement of products being phased out

Replacement of services being phased out

Extension of product/service range within the main market

Extension of product/services range outside the main market

Development of environmentally friendly products/services

Opening of new markets abroad

Opening of new domestic target groups

Innovation Performance (Weerawardena, 2003)

Products and services to the customers

Production methods and processes

Management practices

Marketing practices 